\title{
Corporate sustainability evolvement un- der the guidance of cost control-case study of a zinc and lead metallurgical plant
}

\author{
Chang Shu ${ }^{* 1}$, Guangzhou Zhao ${ }^{2}$ \\ Department of Civil Engineering Management ${ }^{* 1}$, Faculty of Oxbridge ${ }^{2}$, University of \\ Science and Technology \\ "1sshu22@tom.com, ${ }^{2}$ gzz54@yahoo.com.cn
}

\begin{abstract}
Chinese government has put forward the concept of "circular economy" and especially during "the National Twelfth Five Years' Plan" period, circular manufacture mode is emphasized and needs to be further promoted as a coercive policy. Since corporations remain as the main players of circular economy, they are regarded as the forerunner of social sustainable development. Cost strategy, MFCA and environmental damage cost evaluation are introduced in not only as accounting method but also management tool for building up sustainable development system within the corporates. Hereby we illustrate a break-through of a zinc and lead manufacturer's sustainability by using cost control tools.
\end{abstract}

Key words: Corporate sustainability; Cost control; Cost strategy; MFCA; Environmental cost

\section{Introduction}

"Cost Control" covers enormous range of areas, researchers and scholars argue that more researches and efforts under this topic will entail. In one way, it has been criticized and prejudiced as belonging to the leaders with low-level of per- ceived control (externals) and who have been associated with conservative behavior (Baron 1968; Boone et al., 1996; Govindarajan, 1989; Spector, 1982). In the eyes of the conventional strategy contingency theorists, radical development and low-cost control strategies are at the two ends of a strategy analysis matrix diagonal, seemingly contradicted to each other. The strategy contingency theorists think that radical development is aligned with the fast changing environment and low-cost strategy is suggested to better fit into rather stable environment and tends to be adopted by large-scale manufactures.(Oldman and Tomkins 1999 fourstate cost management model), (Chris Carr et al. 2010 adjusted new strategic investment decision making model). "Sustainability science" has been emerged in the last 20 years, and a consensus on the need to view the concept both from intra-generational equity and inter-generational equity makes it hard to define because many conflicting interests and preferences are involved (Editorial of the Cleaner Production, 2007) and also apparently to be against corporation's strategy of cost control, which is profit driven and short-term running. As an interdisciplinary and transdisciplinary field, strategic cost management, environmental accounting and material flow account- 
ing are introduced to assess corporations' management and sustainability.

SCM stresses strategy and can be explained as a coherent branch of cost management systems used for providing financial and competiveness advantage (Sudi Apak et al., 2012). EMA was initiated by the UN in 1998 and MFCA ( material flow cost accounting) derives as a subsidiary branch of EMA

( environmental management accounting ). The prototype of MFCA was developed in Germany (Trade and Industry of JAPAN, 2008). Hereafter, European countries and America organized wide propaganda and efficient implementation in various enterprises such as Dr. Grandel $\mathrm{GmbH}$, etc. and made great success. Japan followed and modified MFCA for increased use(Trade and Industry of JAPAN, 2008).

The Chinese state council has issued "Notice on energy-saving and emissionreduction" and promulgated laws like "the PRC energy law", "Clean Production Promotion Law", as well as order like "Emission charging standards", etc. , exerting the influence of external environmental damage cost evaluation as commandment on production industries. MFCA in China is still stagnating at the theoretical stage, and only few single projects are on trial. So far, typical literature include DENG Mingjun's analysis that traditional EMA and resource accounting method can no longer satisfy the needs of the corporations, and it's especially difficult to confirm the environmental damage cost, which is the core of life cycle evaluation (DENG mingjun, 2009); XIAO Xu's exploration on EMA key factors and assessment methods, based on which MFCA, LIME, internal loss and external damage are combined as comprehensive analysis tool (ZHOU yihong et al. 2011); FENG qiaogen's suggestions that for Chinese corporations whose raw material costs account for a large percentage of the total operation costs, MFCA is well worthy of promotion. As to practices, ZHOU shouhua finished a project of the Ministry of Finance and suggested that corporations should be in pursuit of both the maximization of shareholder's wealth and the fulfillment of social responsibilities including environmental protection and reduction of resource use. XIAO xu cooperated with China Alumina, as well as some other metallurgical plants and steel plants on MFCA projects and valuable innovation suggestions were raised (XIAO xu, 2008, 2009, 2010).

\section{Adaptability of MFCA and envi- ronmental cost assessment in this project}

Environmental Management Cost Accounting is especially suitable for the entities that will impact the outer environment or in the other way around.

Material Flow Cost Accounting succeeds to the most distinguished feature of cost accounting, which is to calculate the working procedure by segmenting the whole manufacturing procedure into several processes by cost assessment, cost projections and planning, thus realizing site controlling and monitoring of manufacturing processes. Besides, MFCA flow chart provides a visible picture about the energy, waste materials, emissions, recycling materials, etc. and thus makes the prompt improvement possible. External environmental damage cost assessment also applies not only for social responsibility but also because it has been embedded in to corporations' cost strategy and affect the final profit sheet.

\section{Case Study}

\subsection{Background}

The company's sustainable development scheme is one of the provincial govern- 
ment's pilot projects and its motto is "reduction, reuse and resource conservation". Its sustainability mode develops with its resource-based competitiveness strategy. The main material EAFD (electric arc furnace dust) is imported from countries like Spain, France, Italy, Czekh, England, Germany, Portugal, etc. So far, it has obtained 8 national invention patterns and is distinguished from other non-ferrous metal corporations as a high-tech corporation.

After its incentive stage's development featured by high innovation and high market orientation during which it is facing with the external environment in a flux, it's undergoing another stage of meeting shareholder's expectation and setting up standardized organizational routines, which is defined as regular and predictable pattern of activity which is made up of a sequence of coordinated actions by individuals (Robert M. Grant, 2001).

When introducing MFCA to the company staff, standardization of accounting form and report and training of relevant skills contribute to the company's organizational routine capacity.

In recent three years, the corporation has gone through significant technological innovation and management improvement with the help of MFCA and environment cost assessment as decision making tools, primarily in two stages.

\subsection{Analysis on the old production line in 2009}

\subsubsection{Cost strategy at the start-up of the production line}

The background at this stage is that challenges and threat come from its rivalsthose state-owned enterprises who have large amount of high-quality ores in storage and are backed up with strong financial capacity; the market situation is challenging, for example, the products are unified in grade, quality and price, and buyers' demands always prevail. This enterprise is obliged to use comparably lowcost resource by resorting to high-tech innovation strategy. Comparing with the normal metallurgical plants that use zinc sulfide concentrate as main materials, which account for about $80 \%$ of zinc resources, it chose zinc oxide ore which falls into the category of the other $20 \%$. The cost advantage is obvious: Pricing of the former is $85 \%$ of the LME price minus $\$ 200 / \mathrm{t}$ of processing fees, and the latter is only $45 \sim 50 \%$ of the current LME price.

\subsubsection{MFCA used to monitor the produc- tion process}

After this decision, MFCA was proposed with the initial motive to increase production efficiency and identify management problems.

i . There are seven basic procedures for MFCA implementation. Targeted production line is the complete production line of this metallurgical plant which is segmented into three processes and all the main products are taken as outcomes.

ii .Three cost centers are set up accordingly, forming the theoretical calculation centers. The working period of the whole production line is about three days and we prefer one month as the calculation base time. Combined use of two data collection methods is recommended (XIAO $\mathrm{xu}, 2008)$. All the manufacturing costs are categorized into four groups as MC, $\mathrm{SC}, \mathrm{EC}$ and waste treatment (MFCA guide by JAPAN, 2007).

Costs data come from the company report, though we have to admit that due to lack of information collection monitoring, the data may be incomplete and piecemeal. And theses cost centers are independent to each other, even the measurement units of materials, energy have not come into agreement, so check and reconfirmation 
of the data with relevant technicians and

Table 1 Positive and Negative Costs Distribution in 2009

(Source: company data and own calculations)

\begin{tabular}{|l|l|l|l|}
\hline Cost Item & Process 1 & Process 2 & Process 3 \\
\hline Positive Product Cost & $32,182,994$ & $34,071,431$ & $40,207,734$ \\
\hline Positive Product Percentage & 0.951 & 0.976 & 0.995 \\
\hline Negative Product Cost & $1,673,970$ & 820,577 & 201,762 \\
\hline Negative Product Percentage & 0.049 & 0.024 & 0.005 \\
\hline
\end{tabular}

MFCA's targeted purpose is to reduce the negative costs into zero, thus the less negative costs, the better.

Comparing with industry standard, optimistic results are shown in this table: the highest negative cost percentage in this project is only around $0.05 \%$, all being sewage, comparing with $20 \%$ or more of normal metallurgical plant's negative costs. Zinc leaching process has realized clean production free of residue. By calculating all the costs in these three processes, process one produces most of the negative products, almost ten times of those produced in process three and twice as much as those in process two (seeing Figure 1) .

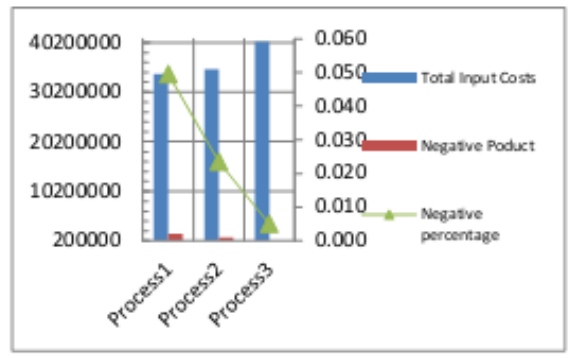

Figure 1 Proportion of negative costs in different processes (Source: company data and own calculation)

Taking further look at the cost distribution among the negative product costs (seeing Figure 2), apparently material costs account for the biggest proportion, being all more than $70 \%$ of all inputs. the current market price are necessary. Among the three processes, system costs percentage varies little with each other, showing consistent management level and standard in different operation centers. Energy costs account for the second largest proportion, and those in process two are about $4 \%$ more than others, calling for attention of immediate measure and efficient improvement.

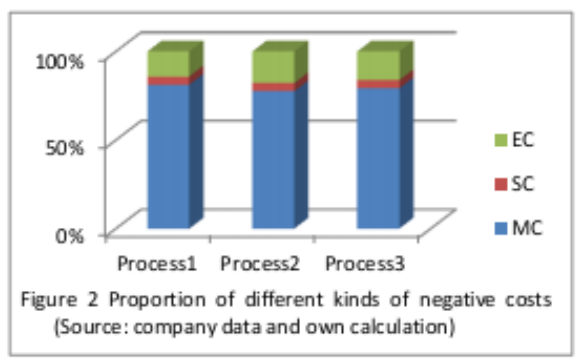

Of all the input costs, those in process three eminently distinguish from others. Since normal lead metallurgical technology adopts lead concentrate as main materials, pricing at $95 \%$ of LME exchange price. The negative product from process one is sewage and sewage treatment technology is a hard nut to crack in all metallurgical plants. Process two produces kiln slag. Negative product from process three remains within a reasonable range. Of all negative cost kinds, material cost is the highest and energy cost in the process two keeps stably high, due to the reason that it uses high quality coking coal as energy resource. In local coal market, price varies from dozens of Yuan to nearly 2000 Yuan per ton, and procurement of coking coal leaves huge space for cost reduction.

\subsection{External environment damage cost evaluation}

According to the No.31 Order promulgated by the National Development and Planning Commission, the Ministry of Finance, The National Environment Pro- 
tection Bureau, The National Economics and Trade Commission, waste emission shall be charged and calculation methods and charging standards are stated therein. Figure 3 is the summarization result of the external environmental damage cost calculation.

We can learn from the figures that in process two, internal costs are relatively low and external costs are quite high, showing high efficiency of internal production management but neglect of environmental protection awareness. Process three is in a reverse condition where few pollutants are discharged accompanying the high dense of material consumption.

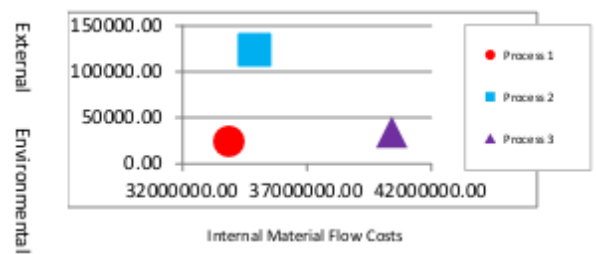

Figure 3 Comparison of "External Environmental Damage Costs" and "Internal Material Flow Costs" in 2009 (Source: company data and own calculations)

\subsection{Improvement suggestions}

Based on the above analysis, according improvement suggestions are raised and listed in the following table:

Table 2 Undermined Problems and Improvement Suggestions

\begin{tabular}{|l|l|l|l|}
\hline Process & Loss type & \multicolumn{1}{|c|}{ Loss description } & \multicolumn{1}{|c|}{ Improvement theme \& target } \\
\hline Process 1 & MC & $\begin{array}{l}\text { Adoption of zinc oxide concen- } \\
\text { trate has largely reduced the mate- } \\
\text { rial costs comparing with zinc } \\
\text { sulfide concentrate, while materi- } \\
\text { al costs still remain too high and } \\
\text { can be further improved. }\end{array}$ & $\begin{array}{l}\text { EAFD (electrical arc furnace dust) may be the most } \\
\text { economical zinc metallurgical material resource of the } \\
\text { world. Its market price is about 60\% of the zinc sul- } \\
\text { fide concentrate, 80\% of the zinc oxide concentrates. } \\
\text { While the alternation of main materials demands ap- } \\
\text { propriate production technology. }\end{array}$ \\
\hline Process 2 & $\begin{array}{l}\text { EC, envi- } \\
\text { ronmental } \\
\text { damage } \\
\text { costs }\end{array}$ & $\begin{array}{l}\text { Use of high quality coking coal } \\
\text { pushes the energy costs to a high } \\
\text { level; tail gas emission is waiting } \\
\text { for further treatment. }\end{array}$ & $\begin{array}{l}\text { Transform the kiln and make it adaptable to the use of } \\
\text { low-quality coal; implementation of innocuous pro- } \\
\text { duction of leaching residues; decontamination device } \\
\text { installation. }\end{array}$ \\
\hline Process 3 & $\begin{array}{l}\text { MC, total } \\
\text { material } \\
\text { flow } \\
\text { costs }\end{array}$ & $\begin{array}{l}\text { High price of lead concentrate } \\
\text { makes lead metallurgy almost } \\
\text { non-profitable. }\end{array}$ & $\begin{array}{l}\text { Reform the lead metallurgy system and mainly focus } \\
\text { on reduction of material costs. }\end{array}$ \\
\hline
\end{tabular}

\subsection{Analysis on new production line}

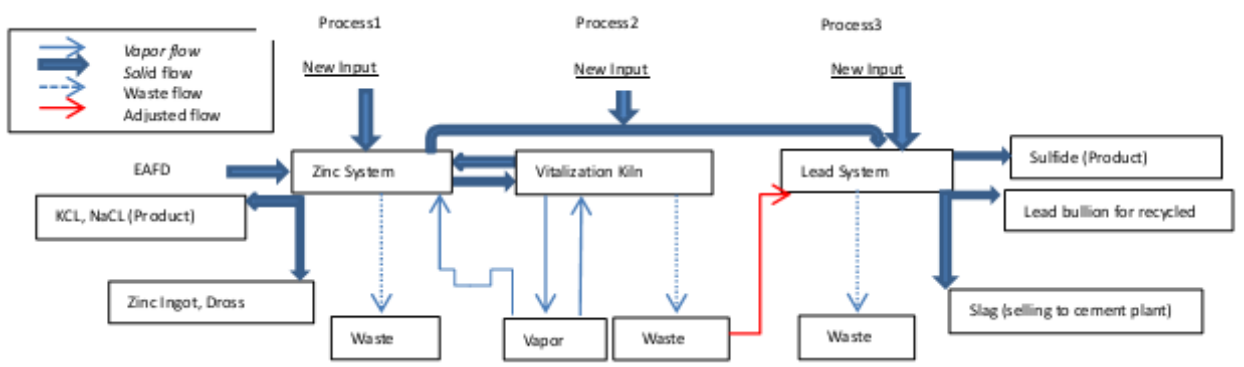

Figure 4 New and altered production line in 2012 
The most notable change is that main material has been changed into electric arc furnace dust. As discussed above, it may be the most economical resource of zinc metallurgy and the supply of such dust can reach as much as 10 million tons worldwide, truly inexhaustible and perfectly matching the theme of sustainable development.

Another successful transformation of the production line lies in the fact that all the wastes are recycled and put into circulation.

Besides, some equipment improvement and new technology innovation haven't been reflected in the above figures but the result of which is embodied in the table below:

Table 3 Positive and Negative Costs Distribution in May, 2012 (Source: company data and own calculations)

\begin{tabular}{|l|c|c|c|}
\hline & Process1 & Process2 & Process3 \\
\hline $\begin{array}{l}\text { Positive } \\
\text { Product }\end{array}$ & 0.999 & 0.987 & 0.994 \\
\hline & 44442869.8 & 30735641.9 & 22292101.5 \\
\hline $\begin{array}{l}\text { Negative } \\
\text { Product }\end{array}$ & 0.0012 & 0.0131 & 0.0058 \\
\hline & 53858.90 & 408043.75 & 129754.05 \\
\hline
\end{tabular}

Comparing the negative cost percentage, that in process two has been reduced from $2.4 \%$ to $1.31 \%$, and that in process three is just about $10 \%$ of that in 2009 , while that in process one dramatically drops to $2.4 \%$ of the former one. In contrary, the positive product efficiency is greatly improved.

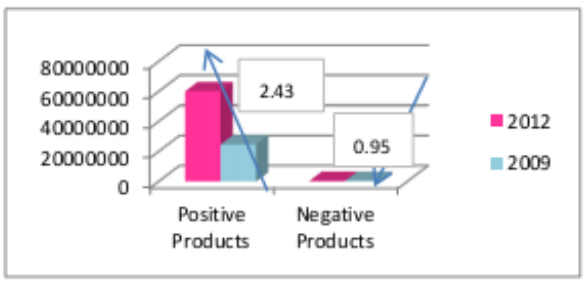

Figure 5 Times of Change of Product Costs (Source: company data and own calculations)

\subsection{Comparison of the results}

By quantifying the product value, we find that the positive products value has been improved by 2.43 times, but at the same time, negative products decrease by 0.96 times. In a short period of time of less than two and half years, technology innovation and sustainable development implementation has brought the corporation into a new era of fast development.

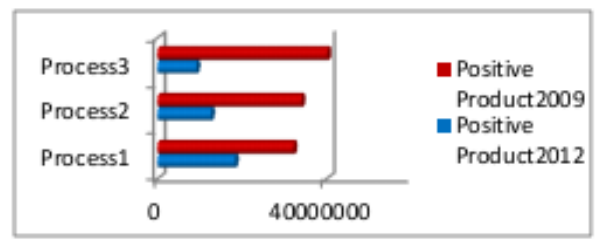

Figure 6 Positive Product Cost Comparison (Source: company data and own calculations)

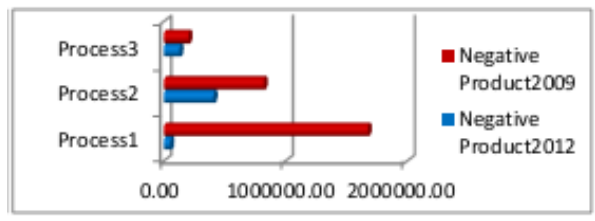

Figure 7 Negative Product Cost Comparison (Source: company data and own calculations)

The left figure describes the positive cost changes in different processes. First of all, the positive costs in 2012 have been reduced to $40 \%$ of those in 2009 , adjusted by positive product value but production scale effect is neglected. This proves a better turnover of about 2.43 times or more. Positive product costs increase gradually in 2009 from process one to process three, with more new inputs added and resulting in escalading cost volumes. The positive product costs in 2012 shows an opposite tendency, meaning costs leave out each process more in the form of final products. While as to negative product costs, the most stunning result is that those in process one has dropped to less than 3\% from 2009 to 2012 , proving a huge success in compa- 
ny's sewage treatment. The company set up a sewage treatment plant and osmosis technology is applied, thus the water after treatment can return to the boiler for reuse, and other water can be returned to different working processes for reuse. This figure makes an interesting illustration about the improvement after the MFCA analysis on the original production line. Material costs drop significantly as a result of main material reform in process one and three. Energy costs are also saved by two thirds, with combined use of low quality coal and oxygen enriched air blast to replace the high quality coal and air blast. System cost is the least one being improved, proving that after technical innovation and improvement of the first stage, the next step to reinforce cost control is system management normalization.

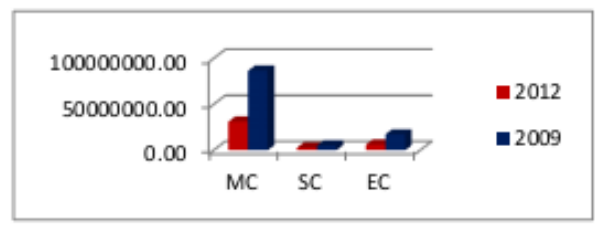

Figure 8 Negative Cost Proportion (Source: company data and own calculations)

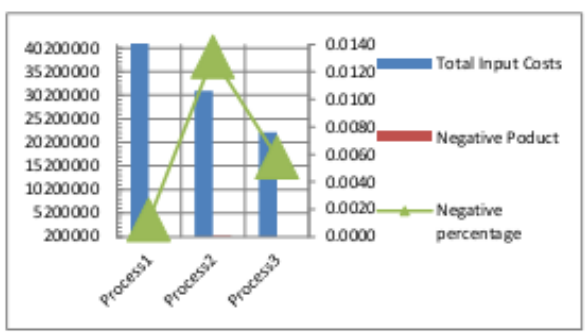

Figure 9 Proportion of negative costs in different processes (Source: company data and own calculation)

This figure displays the negative cost percentage in three processes. Problems remain in the latter two, where wastes are residues: process two produces kiln residue, process three produces water granulated residue, but are both sold out to ce- ment plant and so on. What's more, though still beyond the reach of ideal "zero" target, the negative cost percentage has been well under control (seeing figure $8,0.12 \%$ in process one, $1.31 \%$ in process two and $0.58 \%$ in process three.)

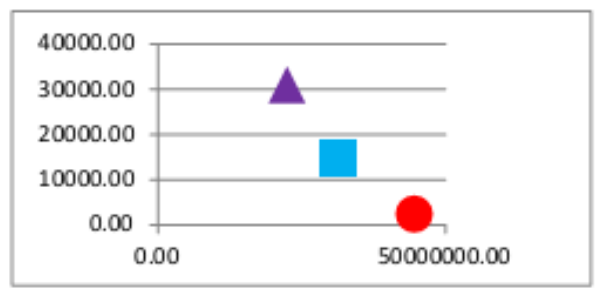

Figure 10 Comparison of "External environmental costs" and "Internal material flow costs" in 2012 (Source: company data and own calculations)

Except for the process three where the external environmental costs keep at the same level, those in the other two are reduced to about one tenth of those in 2009 after a series of envrionemtnal protection reform methods are implemented, where seven methods are applied in zinc system, five methods in Waelz Kiln and only one in lead system. As a result, smoke is reduced by $44 \%$, $\mathrm{SO}^{2}$ reduced by $82 \%, \mathrm{NO}^{\mathrm{X}}$ to zero, arsenic $35 \%$, surfric acid mist $78 \%$, lead $12 \%$, but dust emission volume remains unchanged.

\section{Conclusion}

For any corporations that develop under the theme of "sustainability", they shall carefully incorporate the sustainability principles into their business strategy. 1 . nature is not subject to systematically increasing concentrations of substances extracted from the Earth's crust. 2. Concentrations of substances produced by society. 3. In a sustainable society, human needs are met worldwide in the short- and longterm. 4. Degradation by physical means (Editorial of J. Cleaner Pro., 2007). 
Principle 1: the strategic decision of using Waelz oxide to replace widely used zinc concentrate at the corporation's set-up led to a big saving and temporary cost advantage. Cost strategy can only be the most successful when the advantage resource is incompatible for opponents and hard to imitate, and becoming long lasting, under the prerequisite that the corporation is capable of maintaining the comparative cost advantage. The use of Waelz oxide is proved to be controversial.

Principle two, the corporation has built up a concentration center for EAFD and worldwide procurement further reduces material cost since it is most probably the only corporation of the world that is able to process large scale of secondary raw materials, suppliers may find themselves incompetent in budgeting.

The third principle when applying in this case, long-term goal of sustainable development and short-term goal of cost saving are both met under the guidance of cost strategy and are complementary to each other.

MFCA analysis's most distinct feature of visualizing energy flow help to detect the energy cost concern of the original production line and according treatment has saved more than 10 million Yuan per month for the corporation.

The fourth principle: by evaluating the environmental damage costs, measures are taken to prevent pollution of sewage, tail gas, and solid wastes, achieving a monthly cost saving of near 10 thousand Yuan.

This research is conducted under the background that corporate decision is complicated by the fact that corporations must provide competitive products and services in the short-term while simultaneously seeking to protect and maintain the natural and human resources required for future generations (Artiach et al. 2010). This paper tries to fill the gap.

\section{Acknowledgment}

The author is grateful for the funding and support provided by the corporation and related technicians.

\section{References}

[1] Ana Paula Duarte. 2008. Pro-active behavior induction by integration of sustainability in business strategic management: INOVE project case study. J. Cleaner Pro. 16 (2008) 1127 1132.

[2] Armando H. 2010. Material flow accounting of the copper cycle in Brazil. J. Resources, Conservation and Recycling. 55(2010)20-28

[3] Chris Carr. 2010. Strategic investment decision making practices: a contextual approach. J. Management Accounting Research. 21(2010) 167-184. Spring 114-135.

[4] Christine Jasch, 2003. The use of Environmental Management Accounting for identifying environmental costs. J. Clean Pro.11(2003) 667-676

[5] Environmental Industries Office Industrial Science and Technology Policy and Environment Bureau, Ministry of Economy, Trade and Industry of JAPN. March, 2007. MFCA guide.

[6] Frist H. Wijbenga. 2007. Entrepreneurial locus of control and competitive strategies-the moderating effect of environmental dynamism. J. Economic Psychology. 28(2007) 5666-589

[7] Jaroslava Hyrslova. 2011. Material flow cost accounting-tool for the optimization of corporate production process. 9(1): 5-18

[8] John K. Shank. 1996. Analysis technology investments-from NPV to strategic cost management. J. Management Accounting Research. 7(1996) 185-197

[9] Katsuyuki Nakano, Masahiko Hirao, 2011. Collaborative activity with 
business partners for improvement of product environmental performance using LCA. J. Clean Pro. 19(2011) 1189-1197

[10] LI shaowang. 2011. Discussion on the application of strategic cost management in coal corporation. J. Value Engineering. 1006-4311(2011_230100-01

[11] LUO xiying, XIAO xu. The corporation low-carbon economic development way choice based on MFCA. J.CENT.SOUTH UNIV.(SOCIAL SCIENCE). Feb.Vol.18, 109-114

[12] Michele O'Dwyer. 2005. MNC-SME strategic alliances-A model framing knowledge value as the primary predictor of governance modal choice. J. International management. 11(2005) 397-416.

[13] Ola Eriksson. 2012. Integrated waste management as a mean to promote renewable energy. J. Renewable Energy. 1-5

[14] Peter Bartelmus, 2007 SEEA-2003: Accounting for sustainable development? J. Ecological Economics.61:613-616

[15] Robert Gale. 2005. Environmental management accounting as a reflex- ive modernization strategy in cleaner production. J. Cleaner Pro.14(2006) 1228-1236

[16] Rodrigo Lozano. 2012. Towards better embedding sustainability into companies' systems: an analysis of voluntary corporate initiatives. J. Cleaner Pro. 25(2012)14-26

[17] Sudi Apak. 2012. The use of contemporary development in cost accounting in strategic cost management. J. Social and Behavioral Science. 41(2012)528-534

[18] Xu Xiao, Zhifang Zhou, Jul., 2005. On newest progress about the international guideline of EMA. The fifth international conference on accounting and financial issues with the theme of new development about the modern accounting MC.

[19] YU xiaoling, 2011. Research on strategic cost management and the core competition of corporation. J. Value Engineering. 1006-4311(2011)300108-01

[20] ZHOU yihong. 2011. EA and western economic development. J. Accounting Study. Annual conference in 2010 of EA commission of China Accounting Association. 